\title{
Orally positioning persons with dementia in assessment meetings
}

\author{
Johannes Hjalmarsson Österholm and Christina Samuelsson
}

\section{Linköping University Post Print}

N.B.: When citing this work, cite the original article.

Original Publication:

Johannes Hjalmarsson Österholm and Christina Samuelsson, Orally positioning persons with dementia in assessment meetings, 2015, Ageing \& Society, (35), 2, 367-388.

http://dx.doi.org/10.1017/S0144686X13000755

Copyright: Cambridge University Press (CUP): HSS Journals

http://www.cambridge.org/uk/

Postprint available at: Linköping University Electronic Press

http://urn.kb.se/resolve?urn=urn:nbn:se:liu:diva-103361 
Orally Positioning Persons with Dementia in Assessment Meetings

Johannes H Österholm

Division of Health and Society and Center for Dementia Research [CEDER]

Department of Medical and Health Sciences (IMH)

Faculty of Arts and Science

Linköping University

58183 Linköping

Sweden

e-mail: johannes.h.osterholm@liu.se

Christina Samuelsson

Division of Speech and Language Pathology and Center for Dementia Research [CEDER]

Department of Clinical and Experimental Medicine

Faculty of Health Sciences

Linköping University

58183 Linköping

Sweden

e-mail: christina.samuelsson@liu.se 


\begin{abstract}
In this paper we study if and how persons with dementia are orally positioned by others, and how they position themselves while participating in assessment meetings held in order to discuss access to supportive services. We analyzed five assessment meetings where two older persons (one diagnosed with dementia and one without a dementia diagnosis) participated to investigate whether the person with dementia is positioned differently than the other old person. Interactional phenomena used to position the person with dementia were identified by interactional analysis. We identified six phenomena (ignoring the person with dementia, voicing the feelings, capacity, or opinion of the person with dementia, posing questions implying lack of competence, other's use of diagnosis, self-(re)positioning, and elderspeak) that positioned the person with dementia as an individual with less interactional competence than the other participants. Persons with dementia are often orally positioned as less competent indicating that they suffer further from discrimination than other older persons. Presumably, this has an impact on persons' with dementia possibility to participate in negotiations regarding their future care. The results indicate that social workers should be made aware of that negative positioning exists and how it may affect the persons' with dementia ability to contribute in negotiations about their everyday life. Social workers should be encouraged to find strategies to reduce negative positioning in interaction.
\end{abstract}

Keywords: Ageism, Elderspeak, Interaction, Malignant positioning, Patronizing talk, Formal support 


\section{Introduction}

In Sweden, entitlement for support is assessed by a social worker in an assessment process. Central to the assessment process is the assessment meeting with a representative of the care agency where different kinds of support are discussed. In an assessment meeting with a representative for the agency, the person with dementia must negotiate his or her needs and wishes facing the agency's possibilities. Integrity and self-government are central in the Swedish social services act (2001:453), and also if a person is diagnosed with dementia he or she has the legal right to make the final decision about the use of supportive services. The negotiation during the assessment meeting has great impact on future social care and support, which makes these meetings an interesting case for interactional studies.

Communication is an important tool in the assessment process in institutional settings (Linell, 1990). In the assessment meeting, the professional and the client have different positions, and how they engage in the communication is dependent on these positions. The professional poses questions to the client, who is supposed to give a response, then the response is evaluated by the professional, who decides whether the answer is sufficient to accomplish the assessment or if the answer must be further developed (Hydén, 2000). In this light, the interaction may be claimed to be asymmetrical (Linell, 1990; Linell \& Gustavsson, 1987). Discrimination of older people based on negative age-related stereotypes is a well-established phenomenon (Andersson, 2008), referred to as ageism (Butler, 1969). People tend to adjust their language and speech style depending on whom they address. A basic assumption of research on ageism is that younger conversational partners have been found to sometimes go too far in adjusting their speech style towards older adults. These adjustments are based on negative stereotyped conceptions of older adults rather than on the individuals' needs for adjustments (Harwood, 2007). Younger conversational partners lower their expectations of the older adult's intellect, competence and health status because of negative stereotypes on 
ageing. This reflects a less respectful and a more dominant approach towards the older adult (Hummert \& Mazloff, 2001).

To alter speech styles based on negative stereotypes rather than on personal skills may be considered disrespectful and is referred to as elderspeak, patronizing talk, or secondary baby talk (Harwood, 2007). Caporael and colleagues first described this phenomenon in the 1980s (Caporael, 1981; Caporael, Lukaszewski \& Culbertson, 1983; Caporael \& Culbertson, 1986). These studies comprised naturalistic data, but they focused mainly on the linguistic and phonetic properties of the phenomenon, and no interactional analysis was carried out. Analysis of interaction is often made according to conversation analytic methods, CA, (Hutchby \& Wooffitt, 1997). CA is a theory and methodology that is becoming increasingly common for analyses of interaction involving people with communicative disabilities (Goodwin, 2003). A fundamental methodological principle in CA concerns how a participant's perspective may be brought to the fore by means of targeting what the participants themselves make relevant in the interaction (Hutchby \& Wooffitt, 1997). Typical characteristics of elderspeak are simplified grammar and vocabulary. Other typical characteristics or elements of elderspeak are the use of endearing terms, increased volume, reduced speaking rate, use of repetition, and use of a high and a variable pitch (Harwood, 2007). Elderspeak has been argued to work as a self-fulfilling prophecy where the older adult's communicative skills and competence is diminished if the younger conversational partner treats the older person as less competent (Savundranayagam et al., 2007). Professionals who address older care recipients with elderspeak are perceived as more frustrated, less competent, less confident, and less helpful (Ryan \& Bourhis, 1991). There are also positive aspects of adjusting speech styles towards older adults when these adjustments are based on the individual's needs rather than on negative stereotypes of older adults (Hummert \& Mazloff, 2001). Kemper et al. (1998b) showed that when younger 
caregivers spontaneously used elderspeak they enhanced the older adults' performance, but when communication became connected to a routine task, the use of patronizing talk became more distinctive, and the older adults perceived themselves as less competent. Some features of elderspeak may also enhance interaction, e.g. optimally placed stress and repetitions (Cohen \& Faulkner, 1986; Kemper \& Harden, 1999). Elderspeak may be beneficial for communication since it reduces processing demands through slow rate and simplified syntax and vocabulary (Kemper, 1994). Communication in the institutional context often follows routinized interactional patterns, and thus institutionalized older adults are likely to be exposed to this kind of negative patronizing talk (Kemper et al., 1998b). In the context of health care, elderspeak may impose a feeling in older adults of being ignored and of being perceived as less important (Hummert \& Mazloff, 2001). Furthermore, the physical context has an impact on whether stereotypes reinforce positive or negative perception of older adults. A dependent older care recipient in a hospital setting attracts more elderspeak than an older adult who lives at home (Hummert et al., 1998).

In previous research on language abilities, especially language comprehension, it has been demonstrated that persons with dementia have problems with both verbal and non-verbal comprehension, leading to problems in interaction (Rousseaux, Sève, Vallet, Pasquier \& Mackowiak-Cordoliani, 2010). The knowledge of these problems has resulted in caregiver programs to support communication in interaction with persons with dementia, and evaluations of these programs have shown that caregivers' knowledge of interactional strategies that support memory and communication had positive effects on communication outcome measures (Broughton et al., 2011). Nevertheless, assumptions about communication problems in persons with dementia may also have negative consequences; when addressing persons with dementia, younger conversational partner lower their grammatical complexity, repeat, and provide more extended instructions but also interrupt the person with dementia 
more often to request clarifications (Kemper et al., 1998a). Elderspeak has also been shown to increase resistiveness in personal care (Williams et al., 2009).

Previous research has focused on the outcome of speech adjustments at the group level with experimental and quantitative designs. With a few exceptions (Williams et al., 2009), most of these studies (Hummert \& Mazloff, 2001; Hummert et al., 1998; Kemper et al., 1998a; Ryan \& Bourhis, 1991; Savundranayagam et al., 2007) have been based on non-naturalistic data (e.g. using actors and made-up scripts, situations, or vignettes) to research how younger adults address older people and how older people perceive the way they are addressed. Elderspeak may also be used as a means to position older people as less competent in interaction than younger persons. However, how positions emerge throughout interaction has not been taken into consideration in the elderspeak area. Features of elderspeak might therefore have been overlooked. Thereby, it is interesting to use naturalistic data and to conduct an interactional analysis to study how persons with dementia are positioned by others in assessment meetings, and how they position themselves when applying for supportive services.

One way to understand the recovery of social identity of a person with dementia (Sabat \& Harré, 1999), and as a way to understand the marginalization of power and status of the person with dementia in decision-making situations is to use positioning theory (Bartlett \& O'Connor, 2010). Positioning is an “assignment of fluid 'parts' or 'roles' to speakers in the discursive construction of personal stories that make a person's action intelligible and relatively determinate as social acts" (Van Langenhove \& Harré, 1999, p. 17). Self and other ascriptions of position usually occur naturally in the social context and are mainly a conversational phenomenon; they emerge progressively throughout conversation (Davies \& Harre, 1990). A dominant position in conversation may force other participants into unwanted or unpleasant positions (Harré \& Van Langenhove, 1999). 
For a client with dementia who applies for supportive services, stigmatization could be argued to be double. Because of the dementia diagnosis they are not only treated as older adults but also as having decreased cognitive capacities and thereby decreased capacities to engage in decision-making. This might affect how the person with dementia is positioned in the assessment meeting.

How other persons interact with persons with dementia affects how they are positioned and how they position themselves. Kitwood (1990) argues that a person with dementia might be disabled by others' unintended actions and attitudes towards them; these attitudes are culturally acquired. Kitwood refers to this as "malignant social psychology". A malignant social psychology signifies features of care environment that damages the personhood of the person with dementia. Furthermore, a person with dementia attracts more malignant social psychology than older adults who has not been diagnosed with dementia (Kitwood, 1997). Sabat (2008) discusses something similar - “malignant positioning”. The persons' with dementia actions are often attributed to the disease rather than interpreted in relation to the situation that the person with dementia faces. Cultural stereotypes about persons with dementia and the interpretation of their actions as symptoms (Sabat, 2006) may cause a negative position, which can affect the other conversational partners' communication towards the person with dementia. Due to communicative problems, persons with dementia may not be able to object to how others position them (Sabat, 2006).

\section{Aim}

The overall aim of the present paper is to investigate if and how the person with dementia may be orally positioned by others, and how persons with dementia position themselves while participating in assessment meetings to gain access to supportive services. In this paper we will use detailed interactional analysis of naturalistic conversational data to explore 
interaction in the assessment meeting; how the person with dementia is positioned by the other participants is of special interest.

\section{Method}

\section{Data Collection}

Consecutive sampling was used to collect data from twelve assessment meetings in two Swedish municipalities by the first author. The assessment meeting was then audio-recorded and later transcribed. Of these twelve assessment meetings, five were then selected using preestablished criteria, specifically that they were assessment meetings with two older adults where one of them was diagnosed with dementia. In each of these five assessment meetings (Table 1), there are two older conversational partners present (spouse or sibling); i.e. two older adults where one of them has been diagnosed with dementia. This makes it possible to investigate if the person with dementia is orally positioned differently than the other older adult in the assessment meeting. Thereby we excluded seven assessment meetings from the analysis because there was no other older person present than the person with dementia to investigate if they were positioned differently. The duration of the assessment meetings varied from 17 to 57 minutes with an average of 34 minutes. The assessment meetings took place in different settings; three out of five were held in institutional settings, and the other two took place in the homes of the persons with dementia. All names of persons and places in the present paper are fictive. Ethical approval for this study was obtained through the Regional Ethical Review Board, Dnr 2011/493-31. 
Table 1. Overview of demographic data of the participants.

\begin{tabular}{|c|c|c|c|c|}
\hline Case & Participants & Diagnosis & Place for meeting & Previous supportive services \\
\hline 2 & $\begin{array}{l}\text { Social worker } 1 \text {, person } \\
\text { with dementia, husband, } \\
\text { daughter }\end{array}$ & $\begin{array}{l}\text { Alzheimer's } \\
\text { disease }\end{array}$ & $\begin{array}{l}\text { Short-term care } \\
\text { facility }\end{array}$ & $\begin{array}{l}\text { Short-term care facility } \\
\text { (ended the same week) }\end{array}$ \\
\hline 5 & $\begin{array}{l}\text { Social worker } 1 \text {, person } \\
\text { with dementia, wife }\end{array}$ & Lewy body & $\begin{array}{l}\text { Person with } \\
\text { dementia home }\end{array}$ & $\begin{array}{l}\text { Day activity center (not } \\
\text { able to participate) }\end{array}$ \\
\hline 7 & $\begin{array}{l}\text { Social worker } 5 \text {, person } \\
\text { with dementia, wife, } \\
\text { daughter, assistant nurse }\end{array}$ & Vascular dementia & $\begin{array}{l}\text { Short-term care } \\
\text { facility }\end{array}$ & $\begin{array}{l}\text { Short-term care facility ( } 2 \\
\text { weeks home - } 2 \text { weeks at } \\
\text { the short-term care } \\
\text { facility) }\end{array}$ \\
\hline 8 & $\begin{array}{l}\text { Social worker } 6 \text {, person } \\
\text { with dementia, brother, } \\
\text { distant relative }\end{array}$ & Vascular dementia & $\begin{array}{l}\text { Person with } \\
\text { dementia home } \\
\text { allocated in } \\
\text { sheltered housing }\end{array}$ & $\begin{array}{l}\text { Sheltered housing, home } \\
\text { care } 8 \text { times/day }\end{array}$ \\
\hline 10 & $\begin{array}{l}\text { Social worker } 4 \text {, person } \\
\text { with dementia, wife }\end{array}$ & $\begin{array}{l}\text { Dementia non- } \\
\text { specified diagnosis }\end{array}$ & Day activity center & $\begin{array}{l}\text { Day activity center } 2 \\
\text { days/week }\end{array}$ \\
\hline
\end{tabular}

\section{Data Analysis}

The transcriptions follow the tradition of CA (Hutchby \& Wooffitt,1997), which means that transcriptions are made in exact accordance with what the participants actually said, and translations are made as directly as possible (transcription convention at the end of the article). Transcriptions were analyzed by analysis of interaction, and interactional phenomena used to position the person with dementia were identified. The analysis of interaction was carried out by scrutinizing the recordings and the transcriptions sequentially, searching for patterns in the use of interactional phenomena such as ignoring contributions, talking instead 
of another participant in the interaction, or using of collective pronouns. This analysis was inspired by CA methods (Hutchby \& Wooffitt, 1997). Analyses were made separately by the two authors in order to validate the results.

All audio-recordings were analyzed by perceptual analysis, i.e. listening to them several times, and transcriptions were read repeatedly by both authors separately to reach a sufficient understanding of the interaction. Both authors then identified interactional phenomena used to position the persons with dementia orally or used by the persons with dementia to position themselves orally. In order to calibrate the analysis, one of the previously excluded cases was analyzed by both authors together. Both authors separately analyzed the data again to conduct the final categorization. The occurrence frequency of each interactional phenomenon was counted.

\section{Results}

In the present data, we identified six phenomena (Table 2) functioning to position the person with dementia as an individual with less interactional competence than the other participants in the interaction. 
Table 2. Identified interactional phenomena categorized in category and sub-themes.

\begin{tabular}{|c|c|}
\hline Category & Sub-phenomenon \\
\hline \multirow[t]{3}{*}{ Ignoring } & Talk over the person with dementias head \\
\hline & Initiatives from the person with dementia are not \\
\hline & responded to \\
\hline \multirow[t]{3}{*}{ Voicing } & Voicing of the persons' with dementias feelings \\
\hline & Voicing of the persons' with dementias opinions \\
\hline & Voicing of the persons' with dementias capacity \\
\hline \multicolumn{2}{|l|}{ Questions implying lack of competence } \\
\hline \multicolumn{2}{|l|}{ Other's use of diagnosis to position the person with } \\
\hline \multicolumn{2}{|l|}{ dementia } \\
\hline \multirow[t]{2}{*}{ The person with dementia positioning themselves as } & Competent \\
\hline & Incompetent \\
\hline \multirow[t]{2}{*}{ Elderspeak } & Collective pronouns \\
\hline & Mitigating expressions \\
\hline
\end{tabular}

One of the most common phenomena (Figure 1) is that the other participants talk over the persons' with dementia head. There are also frequent instances where the other participants in the interaction (directly or indirectly) voice the capacities, opinions, and feelings of the person with dementia. Interactional contributions from the person with dementia are also 
ignored by the other participants on several occasions in the data. These three phenomena overlap each other to some extent, since all of them concern ways of marginalizing persons with dementia in interaction, and also ways to express things in the place of the person with dementia. However, it makes sense to treat them as different phenomena as they do slightly different interactional jobs. Another way of diminishing the competence of the person with dementia is to pose questions indicating that the person with dementia is not oriented to person, time, or location. There are also examples when the person with dementia is labeled by others as a person with dementia, and their behavior is explained by the diagnosis. In the present data, there are also several examples of features previously described as elderspeak; collective pronouns, mitigating expressions, and prosodic aspects (high pitch, modifications of pitch range and loud speech).

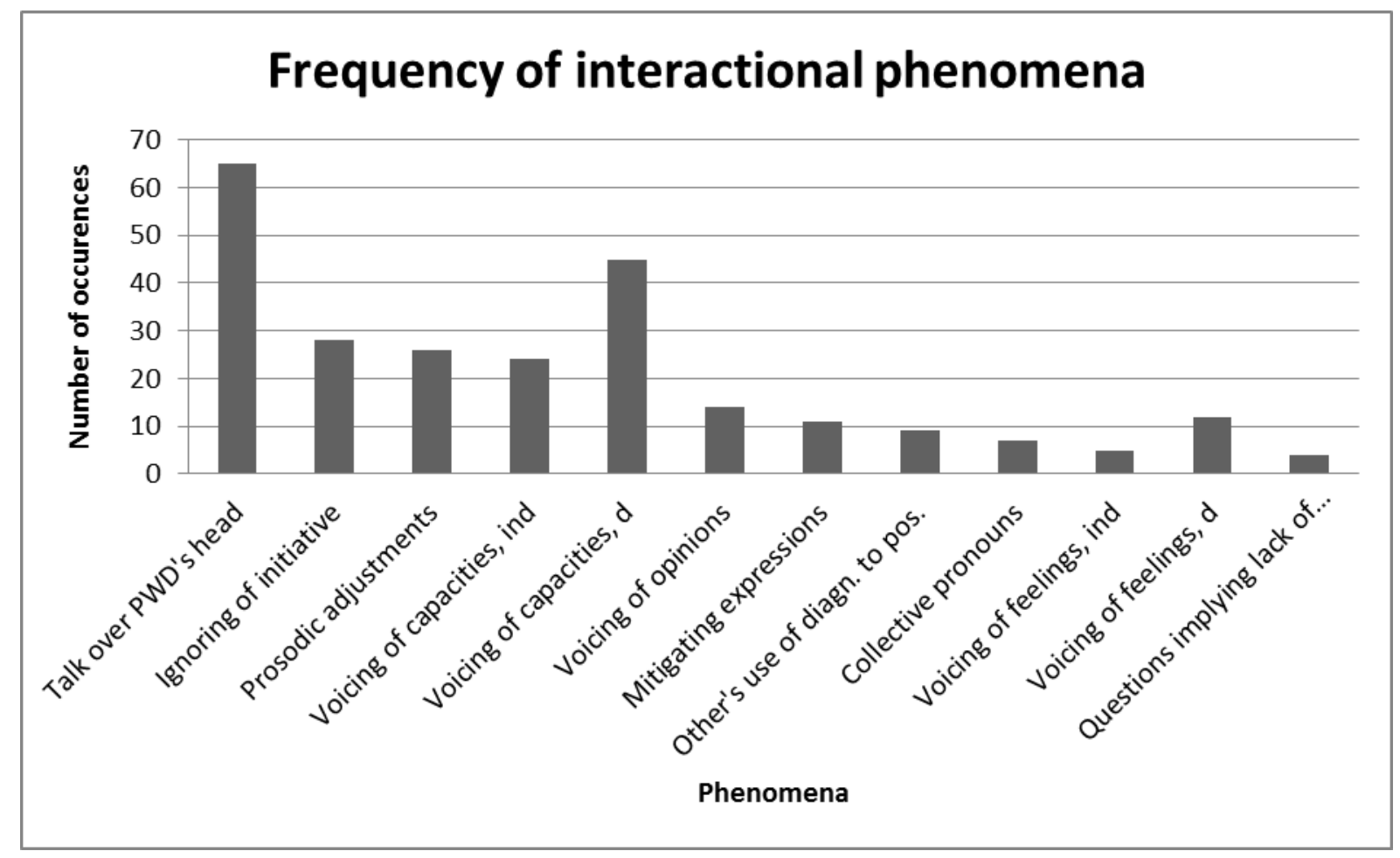

Figure 1. Distribution of identified interactional phenomena calculated in total number of occurrences in the data. 
There are also several examples of the persons with dementia positioning themselves as either competent or incompetent in the data. On ten occasions in the material, the persons with dementia position themselves as competent, and on six occasions they position themselves as incompetent.

In the following, each of the above-identified phenomena is described and exemplified. The means by which the older persons with dementia react and reposition themselves in relation to the examples of malign positioning and elderspeak are also taken into consideration.

Ignoring the person with dementia

The first identified phenomenon used to position the person with dementia as less interactionally competent than the other participants, is to ignore the person with dementia. Either the other participants talked over the head of the person with dementia, or they did not respond at all to initiatives taken by the person with dementia.

The first example illustrates how the other participants talk over the head of the person with dementia, who is a man diagnosed with Lewy Body dementia. This example is taken from a sequence when the possibilities of staying at a short-term facility are discussed.

\section{Example 1.}

Case 5: SW=Social Worker, PWD=person with dementia, $\mathrm{W}=$ wife

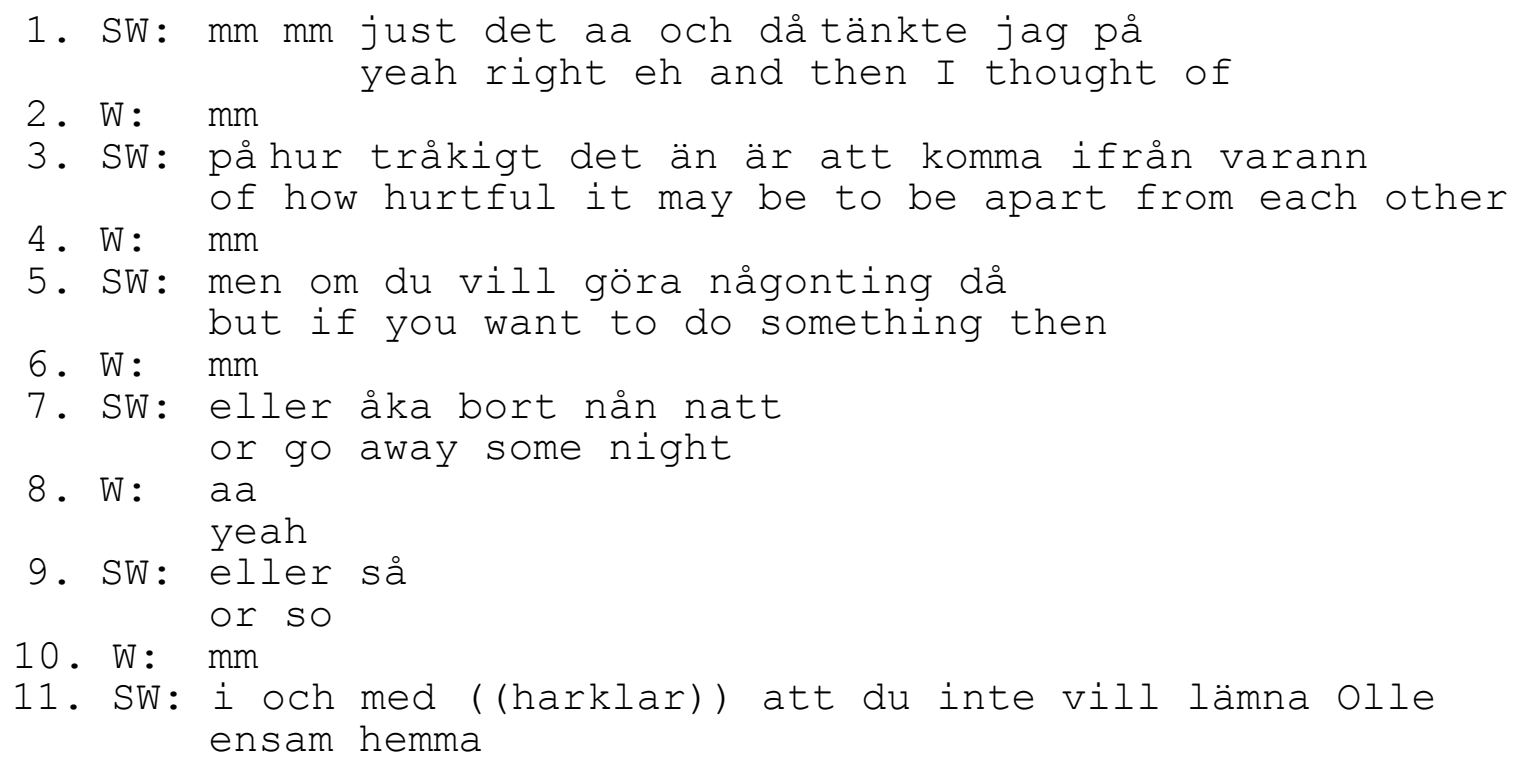




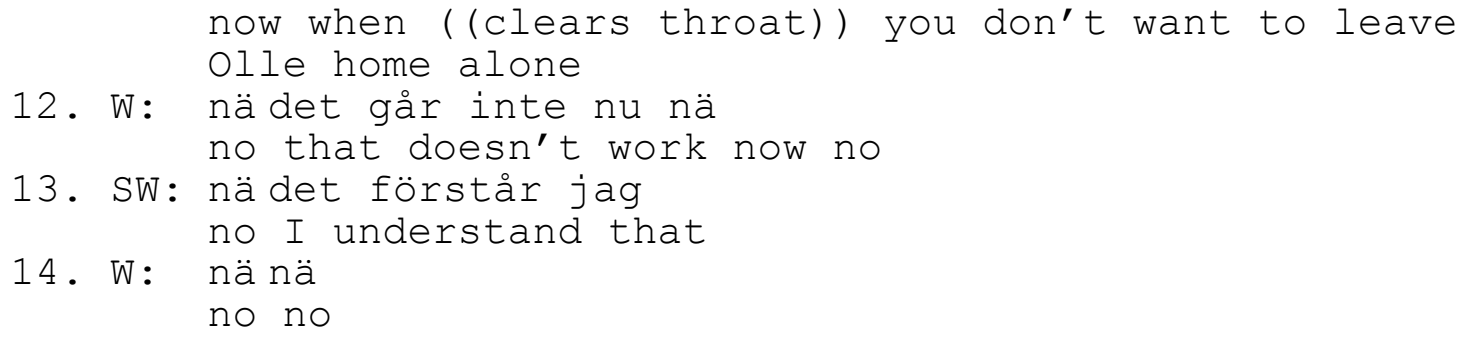

In this example, the social worker brings up the possibilities for the person with dementia to stay a couple of nights at a short-term facility, but it is brought up mainly as a possibility for the wife (lines 5 and 7). The wife mainly responds minimally throughout the sequence, and the person with dementia is sitting at the table during the sequence, but is left out of the conversation. The social worker states that the wife does not want to leave the person with dementia alone in line 11, where he also talks about the person with dementia in the third person by using his first name. The wife responds to this by a confirmation in line 12 , which gets a double confirmation by the social worker in line 13 and yet another confirmation by the wife in line 14.

Example two demonstrates how the persons' with dementia initiative is ignored by the other participants of the conversation. The person with dementia is a woman of 74 years who was diagnosed with dementia about five years ago. The example is taken a few minutes into the recording, and they are discussing the design of the residential home.

\section{Example 2.}

Case 2: $\mathrm{SW}=$ social worker, $\mathrm{PWD}=$ person with dementia, $\mathrm{H}=$ husband, $\mathrm{D}=$ daughter

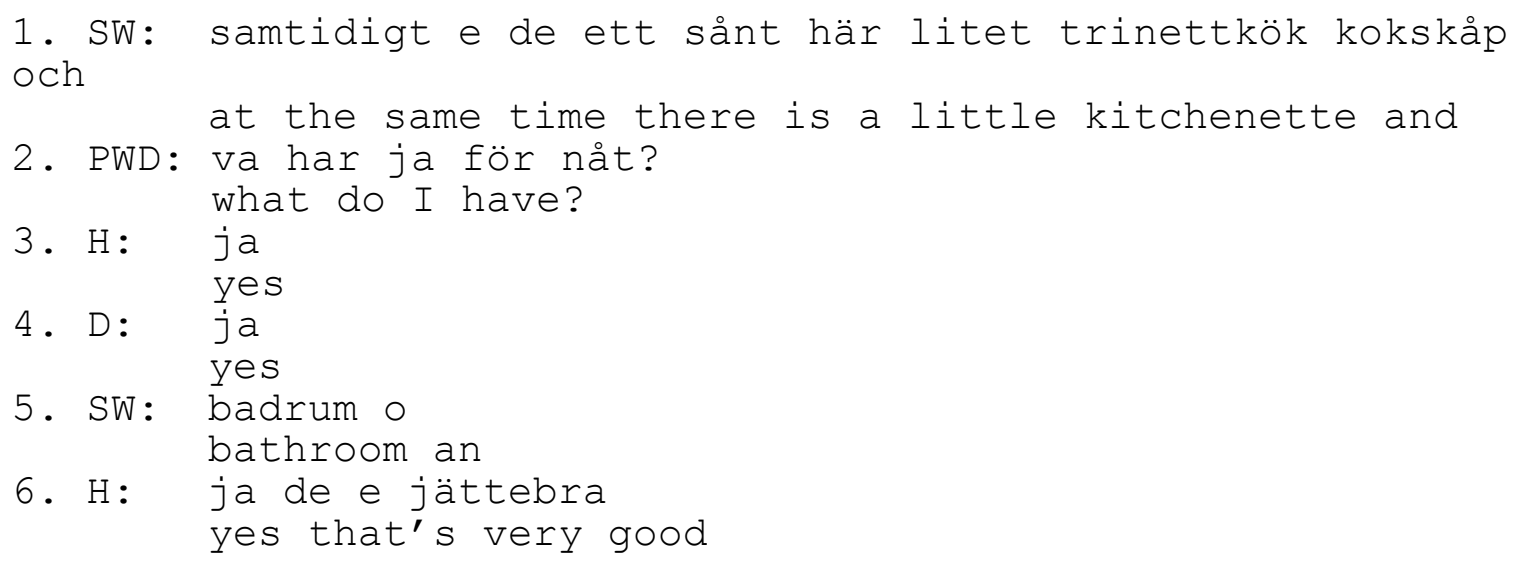


In this example, the social worker is describing the kitchen in the residential home in line 1, which the person with dementia responds to with a request for clarification in line 2 . This request is ignored and the husband and the daughter respond minimally to the social workers' initial contribution in lines 3 and 4 . In lines 5 and 6 , the conversation about the design of the apartment continues, and the person with dementia is more or less left out of the conversation.

Voicing of the feelings, capacity, or opinions of the person with dementia

The second, and perhaps even more salient, way of positioning the older adult with dementia in a depersonalizing way, is to directly or indirectly either voice the feelings, capacity, or opinions of the person with dementia as in example 3, or to talk about the persons' with dementia capacity in his or her presence and over his or her head, as in example 4.

Example 3 is from an assessment meeting between a social worker, a nurse, an 83-year-older man who has had memory and communication problems for a couple of years, his wife, and their daughter.

\section{Example 3.}

Case 7: $\mathrm{SW}=$ social worker, $\mathrm{PWD}=$ person with dementia, $\mathrm{D}=$ daughter, $\mathrm{N}=$ nurse, $\mathrm{W}=$ wife

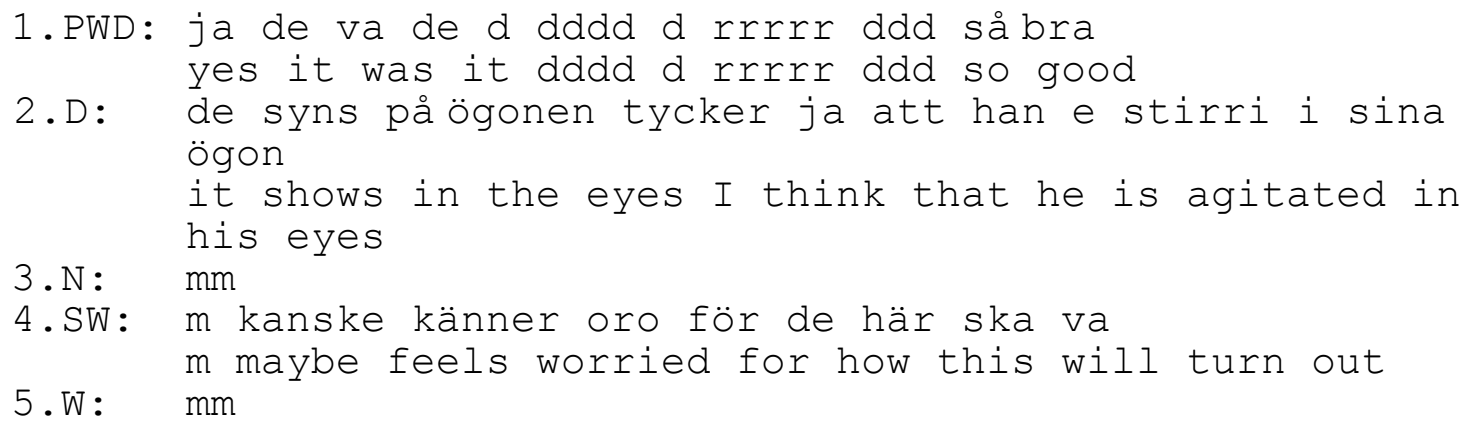

In this example, the person with dementia expresses that something is good, but it is to some extent hidden in a row of unintelligible syllables, in line 1 . This contribution does not get any explicit response; in line 2 the daughter voices the feelings of her father expressing that his 
eyes look agitated. This is confirmed by the nurse's " $\mathrm{mm}$ " in line 3 , and the social worker makes a more explicit voicing of the persons' with dementia feeling in line 4, which is confirmed by the wife in line 5 .

Example 4 is taken from an interaction involving the same participants as in example 2.

\section{Example 4.}

Case 2: $\mathrm{SW}=$ social worker, $\mathrm{PWD}=$ person with dementia, $\mathrm{H}=$ husband, $\mathrm{D}=$ daughter

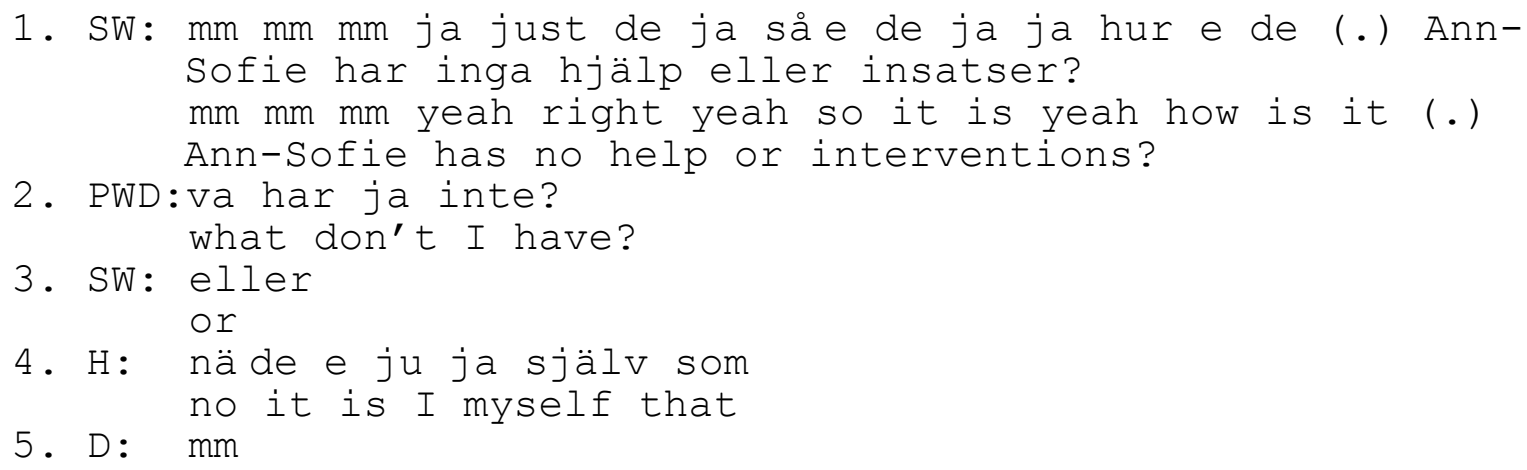

Example 4 illustrates how the person with dementia is positioned as less competent by the fact that the question about her home situation is posed to her husband in line 1 . However, the person with dementia resists this position by responding to the question herself in line 2 . This response is ignored by the social worker, who seeks confirmation from her husband. The husband answers the question in line 4, and the daughter confirms this answer in line 5.

\section{Questions implying lack of competence}

The third phenomenon used to position the person with dementia as less competent is identified in the posing of questions in a way that implies a lack of competence.

Example 5 shows how the person with dementia is addressed by a question assuming that persons with dementia have problems remembering things about themselves, such as where they have been or what they have done. This interactional phenomenon may be an example of how participants innocently treat the persons with dementia in a depersonalizing way that diminishes their feeling of self-worth, e.g. malignant positioning (Sabat, 2006). Example 5 is drawn from a conversation between a social worker, a person with dementia, and his wife. 
The person with dementia is an 84-year-old man, and he has been diagnosed with dementia about six months previous to the recording.

\section{Example 5.}

Case 10: SW=Social worker, PWD=Person with dementia

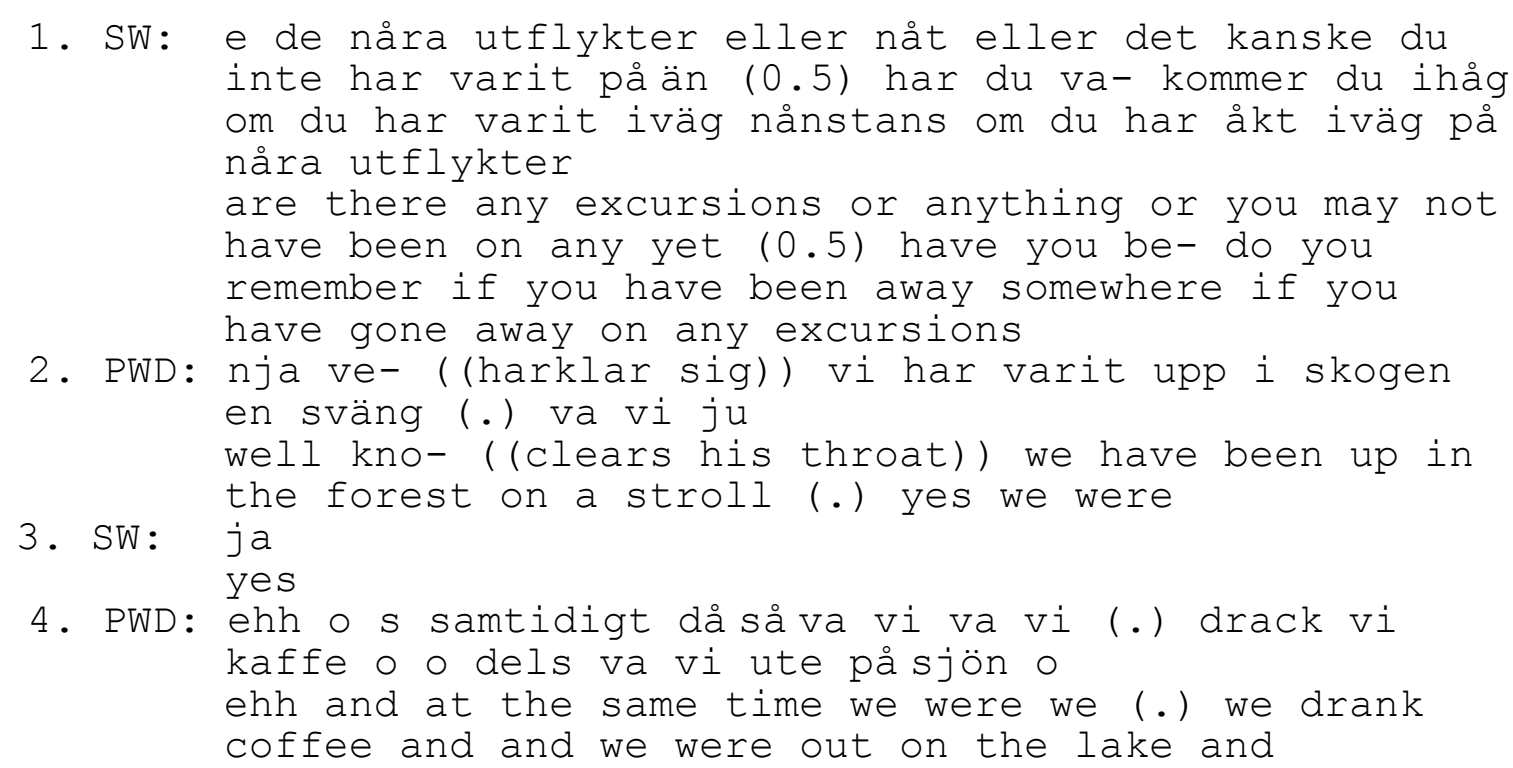

In line 1, the social worker at first starts a question, which she revises into an assumption of the whereabouts of the person with dementia, and then re-revises into a question about the participant's ability to remember. This may be interpreted as positioning the person with dementia as a less competent individual. The person with dementia responds to the question by demonstrating that he remembers what was asked for, thereby positioning himself as a competent interactional partner. The social worker in line 3 responds to this with a minimal response, and the person with dementia then continues his story about the excursion.

Other's use of diagnosis to position the person with dementia

The fourth interactional phenomenon identified to position the person with dementia as less competent than the other participants was to use the dementia diagnosis for ascription of positions. 
In the data there are sequences where the persons with dementia are positioned by others as persons with dementia, and thereby as less competent or dependent on others. This is illustrated in example 6.

\section{Example 6.}

Case 2: $\mathrm{SW}=$ social worker, $\mathrm{PWD}=$ person with dementia, $\mathrm{H}=$ husband, $\mathrm{D}=$ daughter

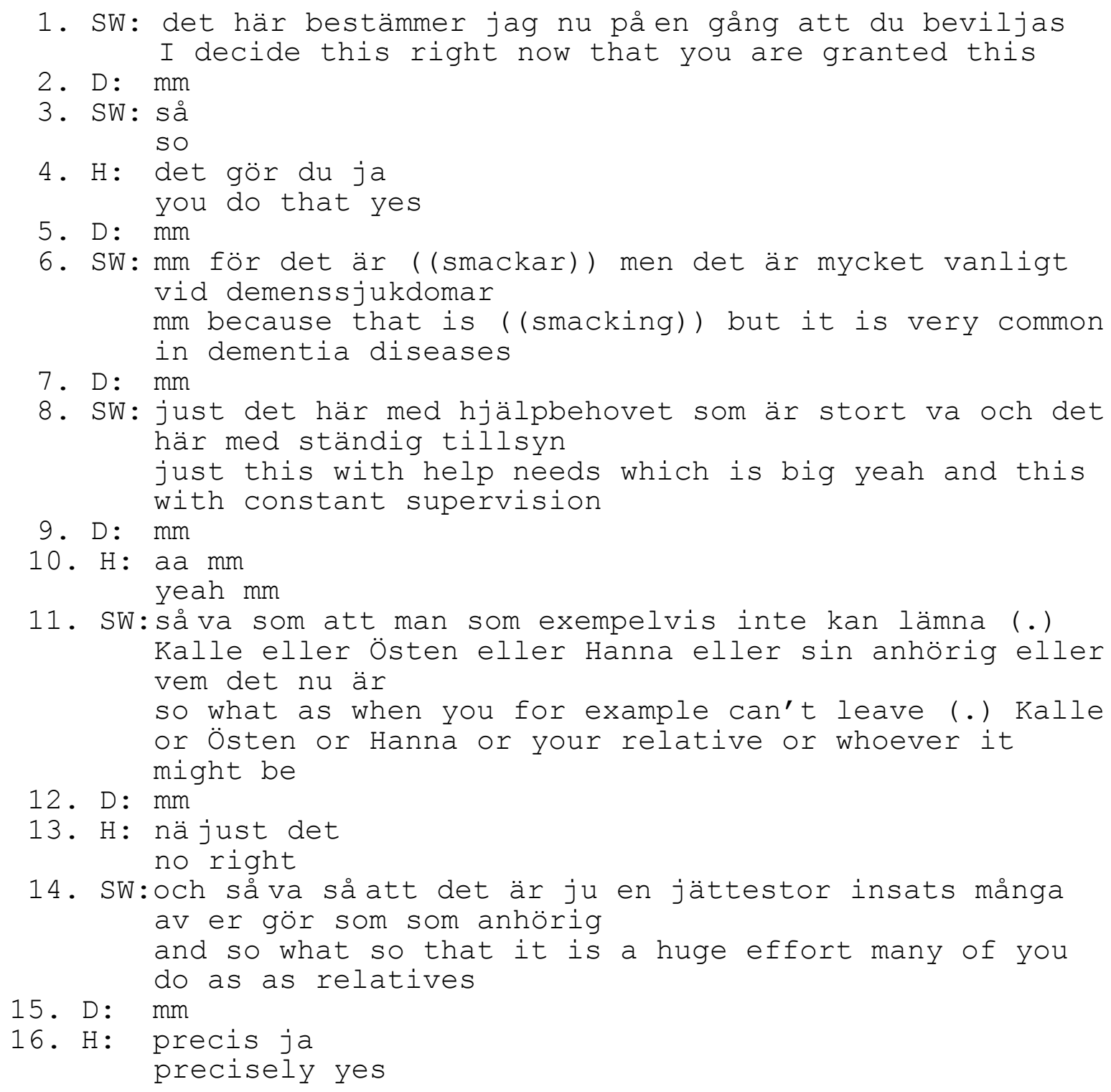

In example 6, the social worker makes a statement about common features of persons with dementia in line 6 , after having decided that the person with dementia will get an allowance for the husband's efforts to support the person with dementia. The social worker continues to position the person with dementia as being someone belonging to a group of people with 
special needs in lines 8 and 10. The daughter and the husband confirm these statements about persons with dementia, thereby contributing to the positioning of the person with dementia as belonging to this group. In line 14, the social worker initiates the closing of the sequence by praising the efforts made by the relatives of persons with dementia, which is confirmed by the daughter in line 15, and the husband in line 16, and he also closes the sequence with his confirmation.

The person with dementia positioning themselves as competent or incompetent

The fifth interactional phenomenon identified was that the persons with dementia position themselves as either competent or incompetent. There are sequences where the persons with dementia either position or re-position themselves as competent or incompetent. There are also sequences where the other participants mitigate the problems of the person with dementia. Example 7 demonstrates on the one hand how the participants try to support the person with dementia by assuring her that she is capable, and thereby position her as competent. On the other hand it shows how the person with dementia comments on her being diminished, possibly an attempt to reposition herself as competent. The discussion from which the example is taken concerns a benefit for carers, and the social worker has asked the husband how much he needs to help his wife.

\section{Example 7.}

Case 2: $\mathrm{SW}=$ social worker, $\mathrm{PWD}=$ person with dementia, $\mathrm{H}=$ husband, $\mathrm{D}=$ daughter

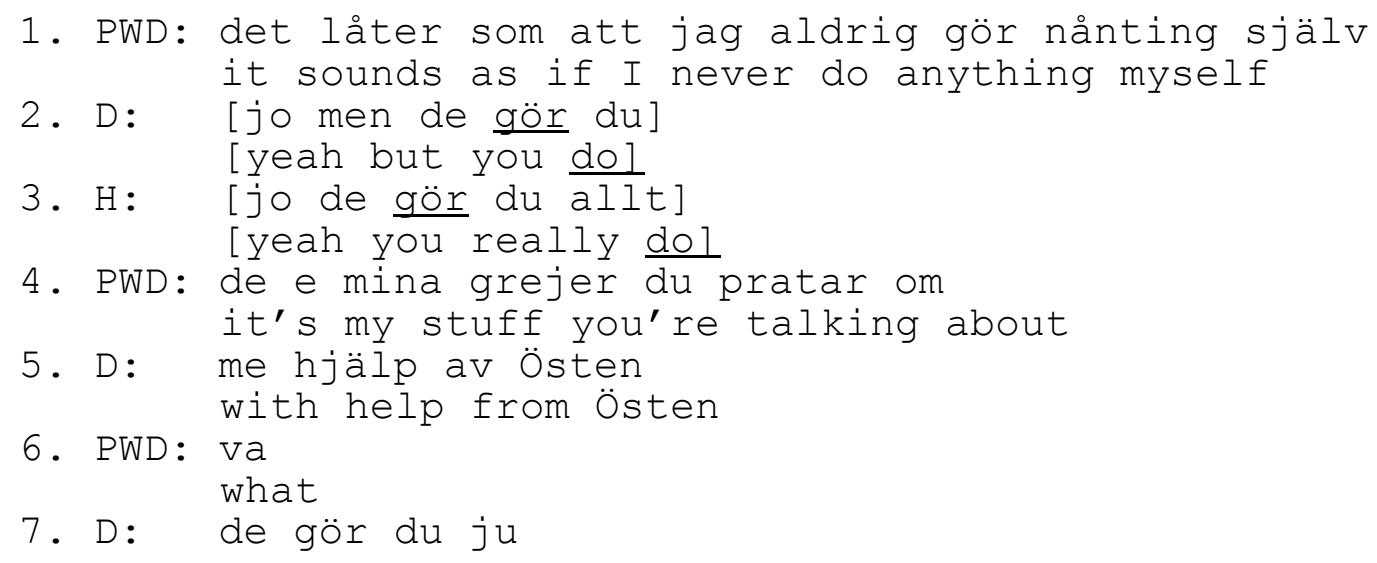




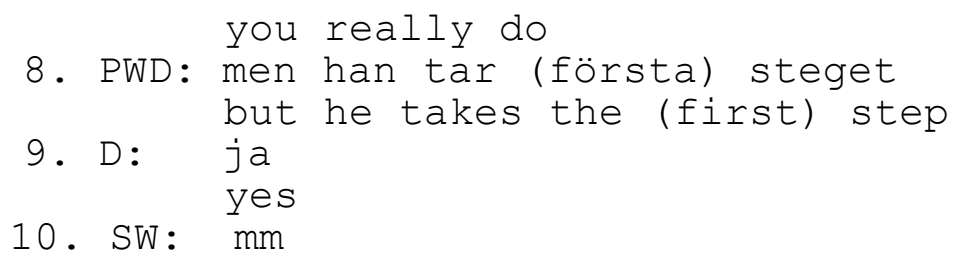

The person with dementia interrupts the discussion by indicating that she is not happy about how she is described, thereby positioning herself as competent; this utterance is produced in a rather firm voice. In lines 2 and 3, the daughter and the husband both assure her that she does things at home, and they both produce their utterances in comforting voices. To respond to the objections made by the person with dementia in a comforting way may be considered a mitigation of the problems that the person with dementia has. The person with dementia states that they talk about her, but this contribution does not get any response. Instead, the daughter continues her previous utterances in line 5, adding that the person with dementia needs some help from her husband. The person with dementia asks for clarification in line 6, whereby the daughter repeats her first comment. In line 8 , the person with dementia comments on her husband's assistance in a somewhat unintelligible way, although indicating that she feels that he takes great responsibility, which is confirmed by both the daughter and the social worker in lines 9 and 10.

\section{Elderspeak}

The sixth identified interactional phenomenon that is used to position the person with dementia as less competent than the other conversational partners was the use of elderspeak. This was accomplished by the use of collective pronouns, mitigating expressions or prosodic aspects, e.g. exaggerated intonation or loud voice.

Example 8 illustrates the use of collective pronouns in interaction with a person with dementia. This example also demonstrates that this form of elderspeak also occurs in 
interactions that are not nursing situations, which is the main situation where elderspeak has been identified in previous research (Caporael, 1981; Williams et al., 2009).

\section{Example 8.}

Case 7: SW=social worker, PWD=person with dementia

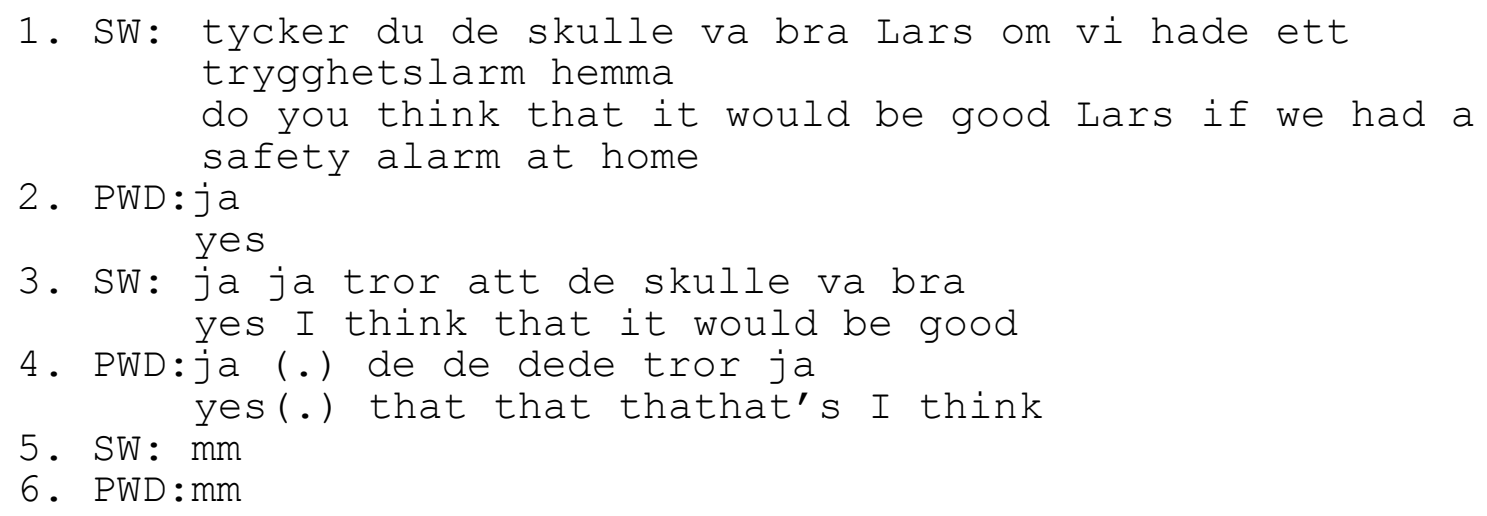

In line 1, the social worker uses we instead of you in the question about getting a safety alarm, although the alarm is going to be installed in the persons' with dementia home. The use of the persons' with dementia first name, which for some older persons may be considered disrespectful (Harwood, 2007), also adds to the sense of diminution in the question. The person with dementia answers with a minimal response in line 2 , and the social worker continues in line 3 by repeating that it would be good to have a safety alarm. In line 4 , the person with dementia elaborates on his previous response, possibly demonstrating interactional competence. The confirmation by the social worker in line 5 could close the sequence. However, the person with dementia also confirms in line 6, i.e. double confirmation, allowing him to close this sequence and get the last word, which may also be interpreted as a way of repositioning himself.

\section{Discussion}

The results have demonstrated that persons with dementia are often orally positioned as less competent in the assessment meetings. The results indicate that the persons with dementia are addressed in a different way than their spouses or siblings, indicating that they suffer even 
further from discrimination than other older persons. There are also examples of how the persons with dementia reposition themselves as competent and capable individuals.

Kitwood (1997) argues that a person with dementia attracts more malignant social psychology than a person who has not been diagnosed with dementia. Previous research (Kemper et al., 1998b) about elderspeak has not reached consensus on whether cognitively impaired older adults are addressed differently than other older adults. The use of interactional data with two older persons where only one was diagnosed with dementia made it possible to show that the person with dementia was positioned differently than the other older adult in the same conversation. In this paper, we have shown that the persons with dementia are positioned as less competent not only by professionals, but also by their next of kin, which gives further support to the concept of dementiaspeak. These results are in line with previous research demonstrating how the social identity of person with dementia may be negotiated through positioning in interaction (Sabat \& Harré, 1999; Bartlett \& O’Connor, 2010). However, the interactions may also have been influenced by the communicative problems that persons with dementia often have (Rousseaux et al., 2010), and the feeling of a need to adjust to these problems by the participants without dementia.

Younger persons have been found to adjust their way of speaking towards older persons based upon negative stereotypes of aging (Harwood, 2007). This occurs frequently in our data, but in this paper we have shown that the persons with dementia sometimes reject others' negative position of them as less competent and thereby re-position themselves as competent. As we have shown in example 7, the person with dementia re-positions herself, and the other participants partly accept this by assuring her that she is competent but still needs help from her husband to accomplish her daily activities. Nevertheless, by rejecting the position as incompetent the person with dementia made the other participants in this sequence stop 
talking over her head, and instead including her in the conversation. These findings raise questions on the impact of elderspeak as a self-fulfilling prophecy (Savundranayagam et al., 2007), as the persons with dementia do not accept the position as less competent implied by the use of elderspeak or other diminishing interactional devices.

In contrast to previous research (Hummert \& Mazloff, 2001; Hummert et al., 1998; Kemper et al., 1998b; Savundranayagam et al., 2007), we use detailed interactional analysis of naturalistic data in the present study (Hutchby \& Wooffitt, 1997). This made the interactional outcomes of the use of positioning and elder/dementiaspeak visible, especially the positioning and re-positioning work done by the persons with dementia themselves. These features may otherwise have been overlooked.

The context in which the conversation takes place is significant to how the older and the younger person perceive themselves and are perceived by others (Hummert \& Mazloff, 2001; Hummert et al., 1998; Kemper et al., 1998a). The context has also been stressed to be important for the occurrence of elderspeak. In this study there were no differences in how the persons with dementia were positioned in the assessment meeting that were dependent on the physical environment. However, the assessment meeting is a task for an institutional organization with a certain purpose, which may explain why we did not find any differences between assessment meetings conducted in the persons' with dementia home context or in an institutional context. It could also be due to the fact that the sample size included in the present study was limited.

In conclusion, persons with dementia are often positioned as less competent than the other participants in the assessment meetings both by younger participants, e.g social workers or children, and by same-aged partners. Presumably, the described dementiaspeak has an impact on persons' with dementia possibility to part take in negotiations regarding their future care. The results of the present study have implications for how we understand both the concept of 
elderspeak and the concept of positioning of older people. We have demonstrated that persons with dementia not only are exposed to elderspeak and malign positioning by other conversational partners, but also contribute to this by positioning themselves as competent or incompetent persons in relation to the disease, which broadens our understanding of elderspeak. Furthermore, the results of the present study indicate that social workers should be made aware of that this type of negative positioning exist and how it may affect the persons with dementia ability to contribute in negotiations about their everyday life. Interactional analysis of assessment meetings may contribute to identification of successful strategies in order to reduce dementiaspeak.

More research is needed to establish if these differences could be argued to be "dementiaspeak" rather than elderspeak. In order to investigate this, a comparable control sample with older adults without dementia in a similar context, i.e. assessment meetings, would be needed. In future research, it would also be relevant to explore the interactional consequences of the use of "dementiaspeak" in assessment meetings.

\section{Transcription conventions}

$\begin{array}{ll}\text { yes } & \text { stress } \\ ? & \text { rising intonation } \\ { }^{\circ} \mathrm{mhm}^{\circ} & \text { cut off word } \\ . \mathrm{hh} & \text { word or utterance pronounced quietly or soft } \\ \text { "really" } & \text { inbreath } \\ (0.5) & \text { pause } \\ (.) & \text { micro pause } \\ () & \text { unclear hearing } \\ \text { [yea] } & \text { overlapping speech } \\ <\text { really> } & \text { speech produced in a slower rate than surrounding talk }\end{array}$




\section{Ethical considerations}

The procedures followed in carrying out this study were in accordance with the ethical standards of the responsible committee of human experimentation, and with the Helsinki Declaration of 1975 as revised in 1983.

\section{Acknowledgements}

We are grateful to Professor Lars-Christer Hydén for his valuable and critical revising of the article. We are also grateful to the participants for their participation in this study. The research reported in this study was supported by a generous grant from the Swedish Riksbankens Jubileumsfond (M10-0187:1).

\section{References}

Andersson, L. (2008). Ålderism [Ageism].Lund: Studentlitteratur.

Bartlett, R., \& O'Connor, D. (2010). Broadening the Dementia debate; Towards Social Citizenship. Bristol: The Policy Press.

Broughton, M., Smith, E. R., Baker, R., Angwin, A. J., Pachana, N.A., Copland, D. A., Humphreys, M. S. Gallois, C., Byrne, G. J., \& Chenery, H. J. (2011). International Journal of Nursing Studies, 48(11), 1436-44.

Butler, R. N. (1969). Age-ism: Another form of bigotry. The Gerontologist 9(4), 243-46.

Caporael, L. (1981). The paralanguage of caregiving: Baby talk to the institutionalized aged. Journal of Personality and Social Psychology, 40(5), 876-84.

Caporael, L., \& Culbertson, G. (1986). Verbal response modes of baby talk and other speech at institutions for the aged. Language and Communication, 6(1-2), 99-112. 
Caporael, L., Lukaszewski, M., \& Culbertson, G. (1983). Secondary baby talk: Judgments by institutionalized elderly and their caregivers. Journal of Personality and Social Psychology, 44(4), 746-54.

Childers, D.G., \& Lee, C.K. (1991). Vocal quality factors: analysis, synthesis, and perception. Journal of Acoustic Society of America, 90, 2394-410.

Cohen, G. \& Faulkner, D. (1986). Does ‘elderspeak’ work? The effect of intonation and stress on comprehension and recall of spoken discourse in old age. Language \& Communication, 6(1-2), 91-8.

Davies, B., \& Harre, R. (1990). Positioning - The discursive production of selves. Journal for the Theory of Social Behaviour, 20(1), 43-63.

Goodwin, C. (2003). Conversation and Brain Damage. Oxford: Oxford University Press.

Harré, R., \& Van Langenhove, L. (1999). The dynamics of social episodes. In R. Harré \& L. van Langenhove (eds), Positioning Theory (pp. 1-13). Oxford: Blackwell Publisher Ltd.

Harwood, J. (2007). Understanding Communication and Aging. California: Sage Publication.

Hummert, M. L., \& Mazloff, D. C. (2001). Older adults' responses to patronizing advice Balancing politeness and identity in context. Journal of Language and Social Psychology, 20(1-2), 167-95.

Hummert, M. L., Shaner, J. L., Garstka, T. A., \& Henry, C. (1998). Communication with older adults - The influence of age stereotypes, context, and communicator age. Human Communication Research, 25(1), 124-51.

Hutchby, I., \& Wooffitt, R. (1997). Conversation Analysis. Oxford: Blackwell.

Hydén, L. C. (2000). Att samtala om socialbidrag [Talking about social benefits]. In A. Puide (eds), Socialbidrag i Forskning och Praktik [Social Benefits in Research and Practice] 
(pp. 224-243). Stockholm: Centrum för utvärdering av socialt arbete, Förlagshuset Gothia AB.

Kemper, S. (1994). Elderspeak: Speech accommodations to older adults. Aging and Cognition, 1(1), 17-28.

Kemper, S., Finter-Urczyk, A., Ferrell, P., Harden, T., \& Billington, C. (1998a). Using elderspeak with older adults. Discourse Processes, 25(1), 55-73.

Kemper, S., Othick, M., Gerhing, H., Gubarchuk, J., \& Billington, C. (1998b). The effects of practicing speech accommodations to older adults. Applied Psycholinguistics, 19(2), $175-92$.

Kemper, S., \& Harden, T. (1999). Experimentally disentangling what's beneficial about elderspeak from what's not. Psychology and Aging, 14(4), 656-70.

Kitwood, T. (1990). The dialectics of dementia: With particular reference to Alzheimer's disease. Ageing and Society, 10(2), 177-96.

Kitwood, T. (1997). Dementia reconsidered - The person comes first. Buckingham: Open University Press.

Linell, P. (1990). De institutionaliserade samtalens elementära former: Om möten mellan professionella och lekmän [The institutionalised appraisals' elementary forms: For meetings between professionals and laymen]. Forskning om Utbildning, 17(4), 18-35.

Linell, P. \& Gustavsson, L. (1987). Initiativ och Respons. Om dialogens Dynamik, Dominans och Koherens [Initiative and Response. About Dialogue Dynamics, Dominance and Coherence]. Linköping: Tema Kommunikation.

Rousseaux, M., Sève, A., Vallet, M., Pasquier, F., \& Mackowiak-Cordoliana, M. A. (2010). An analysis of communication in conversation in patients with dementia. Neuropsychologia, 48(13), 3884-90. 
Ryan, E. B., \& Bourhis, R. Y. (1991). Evaluative perceptions of patronizing speech addressed to elders. Psychology and Aging, 6(3), 442-50.

Sabat, S. R. (2006). Mind, meaning, and personhood in dementia: The effects of positioning. In J. C. Hughes, S. J. Louw \& S. R. Sabat (eds), Dementia: Mind, Meaning, and the Person (pp. 287-302). Oxford: Oxford University Press.

Sabat, S. R. (2008). A Bio-psycho-social approach to dementia. In M. Downs \& B. Bowers (eds), Excellence in Dementia Care. Research into Practice (pp. 70-84). Berkshire England: Open University Press.

Sabat, S. R., \& Harré, R. (1999). Positioning and the recovery of social identity. In R. Harré \& L. Van Langenhove (eds), Positioning Theory (pp. 87-101). Oxford: Blackwell Publisher Ltd.

Savundranayagam, M. Y., Ryan, E. B., Anas, A. P., \& Orange, J. B. (2007). Communication and dementia: Staff perceptions of conversational strategies. Clinical Gerontologist, $31(2), 47-63$.

Social Services Act, SFS 2001:453. (2001). Ministry of Health and Social Affairs, Sweden. http://www.scribd.com/doc/32167396/Social-Services-Act-in-Sweden

Van Langenhove, L., \& Harré, R. (1999). Introducing positioning theory. In R. Harré \& L. Van Langenhove (eds), Positioning Theory (pp. 14-31). Oxford: Blackwell Publisher Ltd.

Williams, K. N., Herman, R., Gajewski, B., \& Wilson, K. (2009). Elderspeak communication: Impact on dementia care. American Journal of Alzheimer's Disease and Other Dementias, 24(1), 11-20. 